\title{
Hierarchical clustering in evaluating inflammatory upper airway phenotypes; increased symptoms in adults with allergic multimorbidity
}

\author{
Tanzeela Hanif, ${ }^{1 *}$ Anu Laulajainen-Hongisto, ${ }^{2,3 *}$ Annika Luukkainen, ${ }^{1}$ Jura Numminen, ${ }^{4}$ Janne Kääriäinen, ${ }^{4}$ Jyri Myller, ${ }^{5}$ \\ Livije Kalogjera, ${ }^{6}$ Heini Huhtala, ${ }^{7}$ Matti Kankainen, ${ }^{8,9}$ Risto Renkonen, ${ }^{1,9}$ Sanna Toppila-Salmi ${ }^{1,2}$
}

\begin{abstract}
Background: Inflammatory upper airway diseases cause significant morbidity. They include phenotypes with different treatment; allergic or non-allergic rhinitis ( $\mathrm{AR}, \mathrm{nAR})$, and chronic rhinosinusitis with or without nasal polyps (CRSwNP, CRSsNP). In clinical practice, these phenotypes are often difficult to distinguish and may overlap.
\end{abstract}

Objective: To evaluate if hierarchical clustering can be used to distinguish these phenotypes based on the presence of nasal polyps, off-seasonal allergic symptoms, and self-reported background characteristics - e.g. atopic dermatitis (AD); and to further analyse the obtained clusters.

Methods: We studied a random sample of 74 CRS (chronic rhinosinusitis) patients, and a control group of 80 subjects without CRS with/without AR (tertiary hospitals, 2006-2012). All underwent interview and nasal examination, and filled a questionnaire. Variables regarding demographics, off-seasonal symptoms, and clinical findings were collected. Hierarchical clustering was performed, the obtained clusters were cross-tabulated and analysed.

Results: Four clusters were identified; 1: "Severe symptoms and CRSwNP" ( $=29), 2$ : "Asymptomatic AR and controls" $(\mathrm{n}=39), 3$ : "Moderate symptoms and CRSsNP" $(\mathrm{n}=36)$, and 4: "Symptomatic and AD" $(\mathrm{n}=50)$. Cluster 1 had most sinonasal symptoms, cluster 3 had a high prevalence of facial pain. The presence of AR did not distinguish CRS groups. Of the AR subjects, $51 \%$ belonged to cluster 4, where AR with off-seasonal airway symptoms and AD predominated.

Conclusion: Hierarchical clustering can be used to distinguish inflammatory upper airway disease phenotypes. The AR phenotype was subdivided by the presence of $\mathrm{AD}$. Adult $\mathrm{AR}+\mathrm{AD}$ patients could benefit from active clinical care of the upper airways also off-season.

Key words: Allergic rhinitis, allergic skin disease, chronic rhinosinusitis, hierarchical clustering, atopic dermatitis

\section{From:}

Haartman Institute, Medicum, University of Helsinki, Helsinki, Finland

2 Skin and Allergy Hospital, University of Helsinki and Helsinki University Hospital, Helsinki, Finland

3 Department of Otorhinolaryngology, University of Helsinki and Helsinki University Hospital, Helsinki, Finland

${ }^{4}$ Department of Ear and Oral diseases, Tampere University Hospital,

Tampere, Finland

${ }^{5}$ Department of Otorhinolaryngology,

Hospital District of Päijät-Häme, Lahti, Finland

${ }^{6}$ Department of Otolaryngology - Head and Neck Surgery,

Zagreb School of Medicine, University Hospital Centre

"Sestre milosrdnice", Zagreb, Croatia

Faculty of Social Sciences, University of Tampere, Tampere, Finland

${ }^{8}$ Finnish Institute of Molecular Medicine, University of Helsinki,

Helsinki, Finland

${ }^{9}$ HUSLAB, Helsinki University Hospital, Helsinki, Finland

\author{
* Should be considered joint first author \\ Corresponding author: \\ Sanna Toppila-Salmi \\ Haartman Institute, PO BOX 21 (Haartmaninkatu 3), \\ FIN- 00014 University of Helsinki, Helsinki, Finland \\ E-mail: sanna.salmi@helsinki.fi \\ List of abbreviations: \\ AC allergic conjunctivitis \\ AD atopic dermatitis \\ AERD aspirin exacerbated respiratory disorder \\ AR allergic rhinitis \\ nAR non-allergic rhinitis \\ CRS chronic rhinosinusitis \\ CRSsNP chronic rhinosinusitis without nasal polyps \\ CRSwNP chronic rhinosinusitis with nasal polyps \\ CT computed tomography scan
}


List of abbreviations (Continued):

IQR interquartile range

MWU Mann Whitney U test

NP nasal polyp

SPSS Statistical Software Package

SPT skin prick test

VAS Visual Analogue Scale

\section{Background}

Chronic inflammatory upper airway diseases include phenotypes, such as allergic or non-allergic rhinitis (AR, nAR), and chronic rhinosinusitis (CRS) with or without nasal polyps (CRSwNP, CRSsNP). ${ }^{1}$

AR affects up to $40 \%$ of the population, often coexisting with allergic conjunctivitis (AC). ${ }^{2}$ Typical symptoms include nasal obstruction, watery discharge, sneezing, nose and eye itching.

AR is usually caused by aeroallergens e.g. pollens (seasonal), mites (perennial), molds, or animal dander. In Finland, pollen allergy is the major cause for AR; the pollen season is clear cut, causing symptoms in spring and summer. Persistent allergic disease due to indoor allergens (i.e. mites) is uncommon. ${ }^{3,4}$ Allergic multi-morbidity has shown to increase morbidity. ${ }^{4,5}$ The coexistence of AR, asthma and atopic dermatitis (AD) is common..$^{5-7}$ Abnormalities in the skin barrier have a role in $\mathrm{AD}$, which may be linked to the development of other atopic diseases such as food allergies, AR and asthma. ${ }^{8}$ Children with $\mathrm{AD}$, especially with early onset food allergies, have a higher risk of developing respiratory allergies. ${ }^{8} \mathrm{AD}$ increases the sensitivity to nonallergenic irritants in children. ${ }^{9}$ Limited knowledge exists of the role of $\mathrm{AD}$ in adults with upper airway diseases. AR patients have symptoms caused by overlapping conditions (e.g. infections, obstructive anatomic structures), and nonspecific irritants. ${ }^{10,11}$ Treatment of AR includes pharmacotherapy, immunotherapy can be considered. ${ }^{2}$

Patients with nAR have rhinitis without evidence of infection or allergen sensitization. Different treatment options exist for nAR subgroups, however, despite its commonness consensus on its diagnostic criteria, epidemiology, and co-morbid role are lacking. ${ }^{12}$

CRS is a multifactorial inflammatory disorder of the nose and paranasal sinuses lasting for minimum 12 weeks; it affects $11 \%$ of the European population. ${ }^{7,13}$ CRS presents with (CRSwNP) and without nasal polyps (CRSsNP). ${ }^{7}$ Up to $4 \%$ have nasal polyps (NP), NP are more common (7\%) in patients with asthma. ${ }^{14,15}$ CRS is usually treated with intranasal corticosteroids, surgery may be considered.?

The diagnostics of CRSwNP, CRSsNP, nAR, and AR are based on history, symptoms, skin prick tests (SPT), and nasal endoscopy. Paranasal sinus imaging, usually computed tomography scans (CT) is performed if necessary. ${ }^{7}$ Phenotypes of chronic inflammatory upper airway diseases may overlap, often being difficult to distinguish in clinical practice. Phenotyping and endotyping are important to develop management. . $^{2,16-20}$

This controlled study aimed at evaluating whether unsupervised hierarchical clustering can be used to distinguish chronic inflammatory upper airway disease phenotypes, based on the presence of NPs, off-seasonal allergic symptoms, and self-reported background characteristics such as $\mathrm{AD}$; and to further analyse the obtained clusters. We hypothesized that the original disease groups can be redrawn based on the clustering method.

\section{Methods \\ Subjects}

This prospective cohort study was performed at the Department of Otorhinolaryngology, Tampere University Hospital, Finland, and Skin and Allergy Hospital, Helsinki University Hospital, 2006-2012.

A random sample of patients $(n=74)$, sent to tertiary care due to CRS symptoms, and evaluated to benefit from sinus imaging, were enrolled, and underwent sinus CT, as previously described. ${ }^{21}$ Airway symptoms and baseline information including SPT results, AD, endoscopic signs of NPs (yes, no), asthma, other diseases, were obtained from a questionnaire and medical records at Tampere University Hospital or Tampere City Hospital. ${ }^{21,22}$ The exclusion criteria were: age < 18 , active, severe general disease (such as active cancer), immunotherapy. In Finland the pollen allergy season is between March and August. Symptom questionnaires were filled between September and February, i.e. outside of the subject's pollen season. CRS was diagnosed according to the EPOS criteria, with total Lund-Mackay score over 0/24. ${ }^{7}$ Signs of NPs were evaluated by patient record information of nasal endoscopy performed at the time of CT scans, and questionnaire.

The controls $(n=80)$ were healthy, or had only AR. They were recruited at the Tampere University Hospital or at Helsinki University Hospital. ${ }^{23,24}$ CRS and the presence of NPs were ruled out by ENT specialists (interview, and nasal endoscopy or anterior rhinoscopy). The AR group consists of healthy volunteer nonsmoking subjects with mild or moderate seasonal controlled AR treated in primary care level. The AR subjects reported a seasonal pollen $A R$ in the interview. The controls' exclusion criteria were positive history of persistent $\mathrm{AR}, \mathrm{CRS}$ and/or previous sinonasal operations, current asthma and/or other diseases than AR, and current smoking. The study was approved by the Pirkanmaa Hospital and the Helsinki University Hospital districts, and their ethical committees (R06187, R07039), (376/13/03/01/10). Written informed consent was obtained from all subjects.

The group sample size $(n=17)$ was based on the median symptom variability score, estimated to differ 1.5 between the following three groups: Co\&AR, CRSsNP and CRSwNP; $a=$ $0,05, \beta=0,8$, STDEV $=1.5$.

\section{Questionnaire of background data}

Allergy was evaluated by questionnaire: I. Have you ever had hay fever or other AR? II. Is this AR doctor-diagnosed? III. Do you get ocular, skin, respiratory or other allergic symptoms (yes, no, don't know). If yes, what symptoms? IV. How many years have you had symptoms? V. How many months per year do you have symptoms? VI. How many days per week do you have symptoms? VII. To which allergens are you allergic? VIII. Has the previously mentioned allergy been detected by an allergy test (what test, where and when)?

The subject was considered to have AR if at least the following questions were responded as follows: I. (yes), IV. ( $\geq 2$ years), VII. ( $\geq 1$ common regional aeroallergen). The subject 
was considered to have atopic dermatitis (AD) if there was a positive response to the question III. (skin symptoms). We formed three groups based on the presence of $\mathrm{AR}$ and/or $\mathrm{AD}$ : No AR/AD; AR only (without $\mathrm{AD}$ ); $\mathrm{AD} \pm \mathrm{AR}$.

The questionnaire also included questions: Do you have doctor-diagnosed asthma (yes, no, don't know)? Do you have aspirin exacerbated respiratory disorder (AERD)? (yes, no, don't know). Describe your current asthma symptoms (none, mild, moderate, severe)? Do you have other diseases (if yes, what)? How many antibiotic courses have you had for sinusitis during the past two years? Are you a current smoker? (yes, no). Have you ever smoked? (yes, no). What is your occupation? Describe your occupational environment? Do you have exposure to poor indoor air? (If yes, please describe). Do you have pets in your living environment? (If yes, please describe). The subjects with risk factors in indoor inhaled air were currently having pet and/or had a risk job, determined as previously described, ${ }^{25}$ and/or reported as having moisture damage at home or at workplace.

\section{Questionnaire of symptoms}

Symptom variables were asked as follows: "Do you currently have one or several of the following symptom(s): obstruction, postnasal drip, nasal discharge, sneezing, nasal itching, sinusitis, pain/pressure in the face or head, ocular symptoms, decreased sense of smell, dyspnea? List the worst symptom(s)? In this study we did not use the sinusitis -responses. Nine symptoms and the sum score of these were used. We recoded the sum score: 0 (no symptoms); 1-2 symptoms = 1 (low variability); 3-4 symptoms (medium variability); 5-9 symptoms (high variability).

The following four current CRS-related symptoms were asked $(\mathrm{n}=145)$ by Visual Analogue Scale (VAS): nasal obstruction, postnasal drip, facial pain/pressure, loss of sense of smell. $0(\mathrm{~cm})$ equals no symptoms, and $10(\mathrm{~cm})$ the worst possible symptoms. The sum score of these was used.

Deviation of the protocol: eight subject of the AR without CRS group lacked information of current symptoms (yes, no), but had VAS responses of the current corresponding symptoms. In these, the presence of nine current symptoms (yes, no) was formed from corresponding VAS scores: VAS $<2 / 10$ $\mathrm{cm}$ "no"; VAS $\geq 2 / 10 \mathrm{~cm}$ "yes".

\section{Allergy tests}

SPT (by trained nurses) was performed on 70 subjects in control group and 13 patients in CRS group. For the rest of the subjects, atopy was evaluated only by a questionnaire without performing SPT. ${ }^{22}$ SPT included 8-16 biologically standardized, allergen extracts: Alder, Birch, Timothy, Smooth meadow, Festuca pratensis, Mugwort, Dandelion, Dog, Cat, Guinea pig, Rabbit, Horse, Cow, Dermatophagoides farinae, Dermatophagoides pteronyssinus, Cladosporium Herbarum, and Latex. Histamine $10 \mathrm{mg} / \mathrm{ml}$ was used as positive, saline as negative control: subjects with SPT saline $>1 \mathrm{~mm}$, or SPT histamine $<3 \mathrm{~mm}$ were withdrawn from SPT analyses, SPT was considered positive when a wheal of minimum diameter $3 \mathrm{~mm}$ formed. Allergen extracts came from Allergopharma, Reinbek, Germany, or ALK A/S, Copenhagen, Denmark. Total serum, birch-specific and timothy-specific IgEs were measured from 46 control subjects.

\section{Data analysis}

Statistical analysis was carried out by SPSS Base 15.0 Statistical Software Package (SPSS Inc., Chicago, IL, USA). Hierarchical clustering was performed by Ward's method with squared Euclidean distance, and standardized by z scores. To represent current off-seasonal airway symptoms and clinical findings, the following variables were selected: gender; nine different sinonasal symptoms (yes, no); the score for variablity of symptoms (none, low, medium, high); positive history of $\mathrm{AR}$ and/or $\mathrm{AD}$ (none, $\mathrm{AR}$ only, $\mathrm{AD} \pm \mathrm{AR}$ ); doctor-diagnosed CRS (yes, no); and presence of NPs by nasal endoscopy or anterior rhinoscopy (yes, no). To avoid selection bias, variables that were unequally distributed in the population were excluded from cluster analysis: asthma or smoking (both were exclusion criteria in control group). Age and gender were also not used, since control subjects were younger than CRS patients. Associations were assessed by the Fisher's exact test (dichotomous) and Kruskal-Wallis and Mann Whitney U (MWU) tests (continuous). Binary logistic regression was used to evaluate the role of $\mathrm{AD}$ in subjects without CRS. Models entering binary logistic regression were adjusted by four potential confounding factors: gender, age, presence of AR, and sensitization pattern (no sensitization, only one allergen type, two or several allergen types). Two-tailed $P$-values of $<0.05$ were considered statistically significant.

\section{Results}

The median (interquartile range [IQR]) age was 28 (2439) years in control group, and 38 (32-54) years in CRS group ( $p<0.001$ by MWU test). The proportion of males was $26 \%$ in control, and $42 \%$ in CRS group ( $p=0.043$, by Fisher's Exact test). Of the subjects in CRS group 31 (43.1\%), and of the subjects in control group $12(16.0 \%)$ reported having other general diseases than asthma (hypertension, hypothyreosis, musculoskeletal diseases, reflux disease, arrhythmia, arthritis/ arthrosis, migraine, depression, epilepsy, otosclerosis, acne, scoliosis, operated cholecystolithiasis, operated feochromocytoma, or resolved melanoma).

Using the cluster approach, a dendrogram was generated based on the parameters described in Methods (Figure 1). Compared to $1-3$ or 5-6 clusters, four clusters were the most equal in size. Table 1 shows the cross tabulation and exploration of the median (IQR) values between the clusters and variables.

\section{Cluster 1}

Twenty-nine adults, with the highest proportion of males (52\%), constituted this cluster, characterized by all CRSwNP patients and $17 \%$ of the CRSsNP patients (Table 1). The highest median sum of VAS scores (Figure 2) and highest median sum of symptoms, with high variability were seen (Tables 1-2). Of the subjects in this cluster, 31\% reported having more than one worst symptom, $48 \%$ reported nasal obstruction as the worst or one of the worst symptoms (Table 3). This group trended to have the highest Lund-Mackay scores. We named this group "Severe symptoms and CRSwNP". 


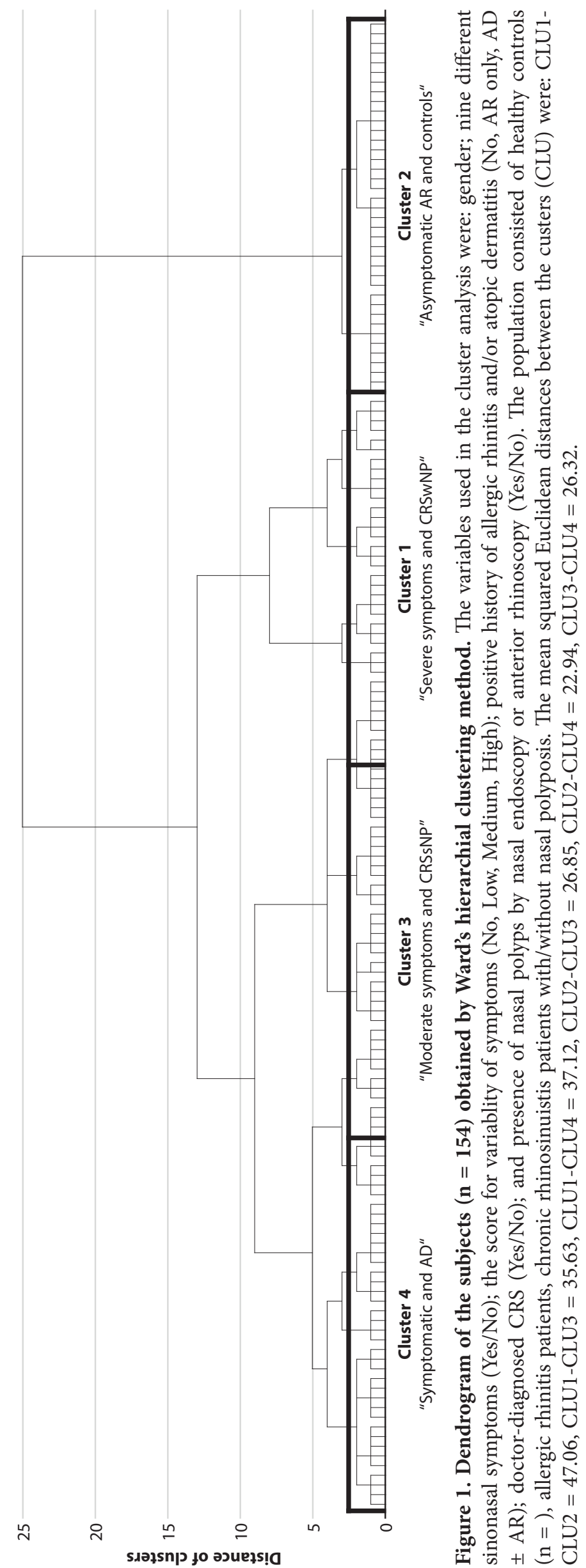


Table 1. Baseline characteristics of the subjects. $n=154$.

\begin{tabular}{|c|c|c|c|c|c|}
\hline & $\begin{array}{l}\text { "Asymptomatic } \\
\text { AR and controls" }\end{array}$ & $\begin{array}{l}\text { "Symptomatic } \\
\text { and AD" }\end{array}$ & $\begin{array}{l}\text { "Moderate } \\
\text { symptoms and } \\
\text { CRSsNP" }\end{array}$ & $\begin{array}{c}\text { "Severe } \\
\text { symptoms and } \\
\text { CRSwNP" }\end{array}$ & \\
\hline & $\begin{array}{l}\text { Cluster } 2 \\
\mathbf{n}=39\end{array}$ & $\begin{array}{c}\text { Cluster } 4 \\
\mathrm{n}=\mathbf{5 0}\end{array}$ & $\begin{array}{c}\text { Cluster } 3 \\
\mathrm{n}=36\end{array}$ & $\begin{array}{c}\text { Cluster } 1 \\
\mathrm{n}=29\end{array}$ & $p$ \\
\hline Male gender, n (\%) & $11(28.2)$ & $14(28.0)$ & $12(33.3)$ & $15(51.7)$ & .15 \\
\hline Age (years); median (IQR) & $29.5(24.3-40.3)$ & $29.0(24.9-40.3)$ & $37.2(31.2-45.2)$ & $43.1(34.0-59.0)$ & .001 \\
\hline Chronic rhinosinusitis, $\mathrm{n}(\%)$ & $1(2.6)$ & $14(28.0)$ & $34(94.4)$ & $25(86.2)$ & $<.001$ \\
\hline Nasal polyps, n (\%) & $0(0)$ & $0(0)$ & $0(0)$ & $15(51.7)$ & $<.001$ \\
\hline Lund-Mackay score of sinus CT scans, median (IQR) ${ }^{1}$ & N/A & $7(2-9.5)$ & $4(2-9)$ & $9.5(5-14)$ & .057 \\
\hline Sinus surgery and/or polypectomy ${ }^{2}$ & & & & & $<.001$ \\
\hline No & $39(100)$ & $45(90)$ & $14(38.9)$ & $11(37.9)$ & \\
\hline One & $0(0)$ & $3(6.0)$ & $13(36.1)$ & $10(34.5)$ & \\
\hline Two & $0(0)$ & $2(4.0)$ & $6(16.7)$ & $7(24.1)$ & \\
\hline Three of more & $0(0)$ & $0(0)$ & $3(8.3)$ & $1(3.4)$ & \\
\hline Patient group & & & & & $<.001$ \\
\hline Control & $15(38.5)$ & $8(16.0)$ & $1(2.8)$ & $1(3.4)$ & \\
\hline AR & $23(59.0)$ & $28(56.0)$ & $1(2.8)$ & $3(10.3)$ & \\
\hline CRS & $1(2.6)$ & $7(14.0)$ & $18(50.0)$ & $4(13.8)$ & \\
\hline $\mathrm{CRS}+\mathrm{AR}$ & $0(0)$ & $7(14.0)$ & $16(44.4)$ & $6(20.7)$ & \\
\hline CRSwNP & $0(0)$ & $0(0)$ & $0(0)$ & $15(51.7)$ & \\
\hline Allergic rhinitis, n (\%) & $23(59.0)$ & $35(70.0)$ & $17(47.2)$ & $19(65.5)$ & .18 \\
\hline Asthma & $2(5.3)$ & $0(0)$ & $3(8.3)$ & $15(51.7)$ & $<.001$ \\
\hline Moderate to severe asthma symptoms, n (\%) & $0(0)$ & $0(0)$ & $0(0)$ & $5(17.2)$ & $<.001$ \\
\hline \multicolumn{6}{|l|}{ Self-reported disorders, n (\%) } \\
\hline Allergic lower airway symptoms & $0(0)$ & $0(0)$ & $2(14.3)$ & $8(53.3)$ & .017 \\
\hline AERD & $1(2.6)$ & $0(0)$ & $1(3.6)$ & $6(24.0)$ & .001 \\
\hline $\mathrm{AD}$ & $6(16.2)$ & $22(44.9)$ & $7(25.9)$ & $8(32.0)$ & .037 \\
\hline Ocular allergy & $0(0)$ & $1(12.5)$ & $4(28.6)$ & $5(33.3)$ & .69 \\
\hline Other diseases & $3(8.6)$ & $14(28.6)$ & $14(40.0)$ & $12(42.9)$ & .005 \\
\hline \multicolumn{6}{|l|}{ Serum values $(\mathrm{ku} / \mathrm{L})$; median $(\mathrm{IQR})^{3}$} \\
\hline Total IgE & $22(14-65)$ & $51.0(19-119)$ & $45.50(19-72)$ & $160(156-180)$ & .074 \\
\hline Birch-specific IgE & $0.02(0-7.5)$ & $9.9(0-25)$ & $15.6(0-31.2)$ & $0.03(0.02-1.7)$ & .58 \\
\hline Timothy-specific IgE & $0.01(0.00-0.28)$ & $0.00(0.00-0.87)$ & N/A & $0.01(0.01-0.18)$ & .64 \\
\hline SPT positive values, $\mathrm{n}(\%)^{4}$ & & & & & .90 \\
\hline No & $11(34.4)$ & $10(30.3)$ & $11(34.4)$ & $1(12.5)$ & \\
\hline To only one allergen type & $7(21.9)$ & $10(30.3)$ & $7(21.9)$ & $2(25.0)$ & \\
\hline To several allergen types & $14(43.8)$ & $13(39.4)$ & $14(43.8)$ & $5(62.5)$ & \\
\hline
\end{tabular}


Table 1. (Continued)

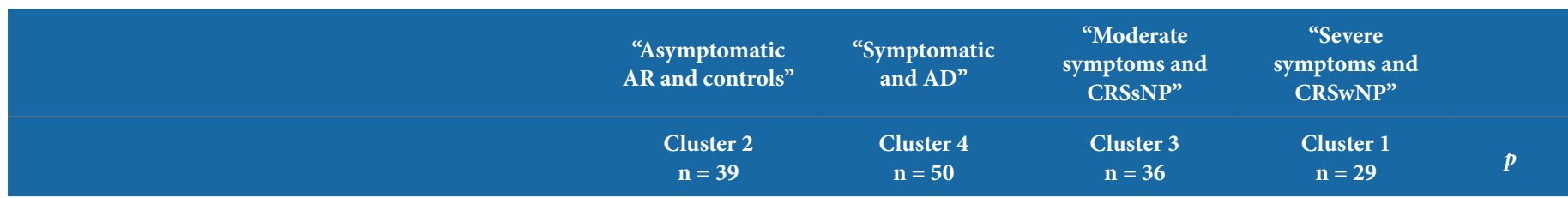

SPT positive values, $\mathrm{n}(\%)$

\begin{tabular}{|c|c|c|c|c|c|}
\hline Pollen(s) & $20(62.5)$ & $23(67.9)$ & $6(60.0)$ & $7(87.5)$ & .56 \\
\hline Animal dander(s) & $14(43.8)$ & $13(39.4)$ & $4(40.0)$ & $5(62.5)$ & .71 \\
\hline Mite(s) & $2(6.3)$ & $1(3.0)$ & $1(10.0)$ & $0(0)$ & .67 \\
\hline Mould(s) & $1(7.1)$ & $0(0)$ & $0(0)$ & $0(0)$ & 1.0 \\
\hline Duration of symptoms (y); median (IQR) & $0(0-7.0)$ & $5.0(2.5-15.0)$ & $3.0(0.5-5.0)$ & $5.0(2.5-13.0)$ & .073 \\
\hline Sum of 9 symptoms; median (IQR) ${ }^{4}$ & $0(0-0)$ & $3(2-4)$ & $3(3-4.5)$ & $6(5-7)$ & $<.001$ \\
\hline Antibiotic courses due to ARS per 2 y; median (IQR) & $0(0-0)$ & $0(0-1.5)$ & $4(2-7)$ & $2(0-6.5)$ & $<.001$ \\
\hline Allergy symptoms months/y; median (IQR) & $0.5(0-2)$ & $2.5(0-4.5)$ & $0(0-3)$ & $0.5(0-12)$ & .042 \\
\hline \multicolumn{6}{|l|}{ Environmental exposure } \\
\hline Self-smoking, n (\%) & $1(2.6)$ & $2(4.0)$ & $9(25.0)$ & $5(17.9)$ & .003 \\
\hline Risk factors in indoor inhaled air $^{5}$ & $11(36.7)$ & $9(32.1)$ & $1(50.0)$ & $2(50.0)$ & .80 \\
\hline Indoor allergy and regular exposure to indoor allergens ${ }^{6}$ & $0(0)$ & $3(10.7)$ & $0(0)$ & $0(0)$ & .44 \\
\hline
\end{tabular}

${ }^{1}$ Sinus computed tomography (CT) scans were performed to CRS patients ( $\mathrm{n}=74$ ) only at the time of symptom questionnaire. ${ }^{2}$ Previous sinus surgery and/or polypectomy and/or the ones during follow-up of in average 8 years. ${ }^{3}$ performed only to 46 subjects. ${ }^{4}$ The following nine symptoms were asked off-seasonally (yes, no): obstruction, postnasal drip, nasal discharge, sneezing, nasal itching, pain/pressure in the face or head, ocular symptoms, decreased sense of smell, dyspnea. ${ }^{5}$ performed only to $83(53 \%)$ of all subjects. ${ }^{6}$ A total of 64 and 61 responses, respectively. AD $=$ atopic dermatitis, AR $=$ allergic rhinitis, SPT $=$ skin prick test., ${ }^{2}$ Seasonal AR = allergic rhinitis symptoms $\leq 5$ months/year and/or no mite sensitivity (analysed only from subjects with allergic rhinitis), ${ }^{3}$ subject-reported disease, other than CRS, AR or asthma, ${ }^{4}$ at least one SPT+ value to one allergen type (Pollen/animal dander/mite). ${ }^{5}$ SPT + values to $\geq 2$ allergen types. $p$ values for cluster-wise comparisons by Kruskal-Wallis (continuous variables) or by Fisher's exact test (dichotomous variables). IQR = interquartile range, in which Q1 $=25 \%$ percentile, Q3 = 75\% percentile.

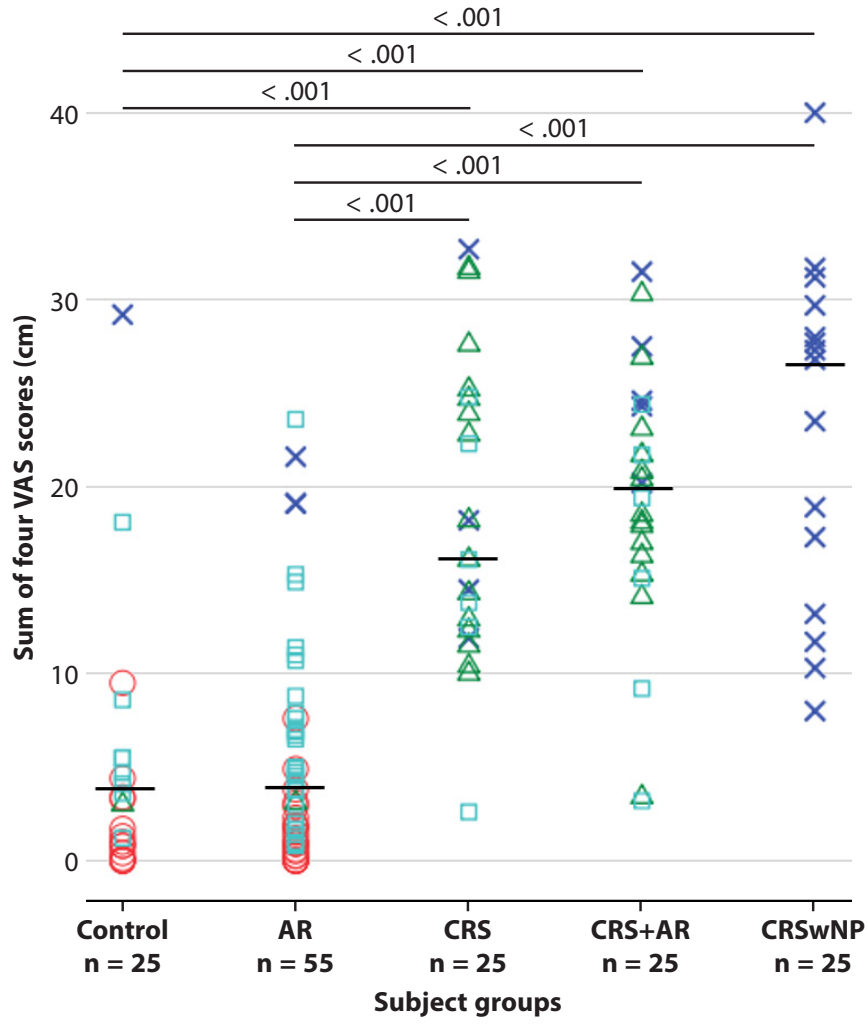

\author{
Clusters by Ward's method \\ X Cluster 1 "Severe symptoms and CRSwNP" $(n=28)$ \\ $\triangle$ Cluster 3 "Moderate symptoms and CRSsNP" $(n=31)$ \\ Cluster 2 "Asymptomatic AR and controls" $(n=38)$ \\ $\square$ Cluster 4 "Symptomatic and AD" ( $n=48)$
}

Figure 2. Scatterplot showing the sum of four CRS-related current symptoms in the five different subject groups. The symptoms were asked off-seasonally from 145 subjects by Visual Analogue Scale (VAS): nasal obstruction, postnasal drip, facial pain/pressure, loss of sense of smell. $0(\mathrm{~cm})$ meaned no symptoms at all and $10(\mathrm{~cm})$ meant the worst possible symptom. Cases are labeled by the four clusters obrained by Ward's method. $\mathrm{AR}=$ allergic rhinitis, $\mathrm{CRS}=$ chronic rhinosinusitis, CRSwNP = CRS with nasal polyps. The median values are shown by horizontal lines. $p$-values by MWU test. Only statistically significant 0 -values $(<0.05)$ are shown. 
Table 2. Number and proportion (\%) of positive responses to the (off-seasonal) symptom questionnaire, if the symptom is currently presenting, (A.) in $\mathbf{n}$ four clusters obtained by Ward's method, (B.) in subject groups. $p$ values by Fisher's exact test. $\mathrm{AD}=$ atopic dermatitis.

\begin{tabular}{|c|c|c|c|c|c|c|}
\hline A. & $\begin{array}{l}\text { "Asymptomatic } \\
\text { AR and controls" }\end{array}$ & $\begin{array}{c}\text { "Symptomatic } \\
\text { and } A D "\end{array}$ & & $\begin{array}{l}\text { "Moderate } \\
\text { symptoms and } \\
\text { CRSsNP" }\end{array}$ & $\begin{array}{c}\text { "Severe } \\
\text { symptoms and } \\
\text { CRSwNP" }\end{array}$ & \\
\hline & $\begin{array}{c}\text { Cluster } 2 \\
\mathbf{n}=39\end{array}$ & $\begin{array}{c}\text { Cluster } 4 \\
\mathrm{n}=\mathbf{5 0}\end{array}$ & & $\begin{array}{c}\text { Cluster } 3 \\
\mathbf{n}=36\end{array}$ & $\begin{array}{c}\text { Cluster } 1 \\
\mathbf{n}=29\end{array}$ & $p$ \\
\hline \multicolumn{7}{|l|}{ Current symptoms, n (\%) } \\
\hline Wheeze & $0(0)$ & $3(6)$ & & $1(3)$ & $15(52)$ & $<.001$ \\
\hline Loss of sense of smell & $0(0)$ & $9(18)$ & & $4(11)$ & $19(66)$ & $<.001$ \\
\hline Ocular irritation symptoms & $0(0)$ & $9(18)$ & & $12(33)$ & $15(52)$ & $<.001$ \\
\hline Sneeze & $0(0)$ & $27(54)$ & & $9(25)$ & $15(52)$ & $<.001$ \\
\hline Nose itching & $1(3)$ & $20(40)$ & & $10(28)$ & $13(45)$ & $<.001$ \\
\hline Nasal discharge & $3(8)$ & $24(48)$ & & $12(33)$ & $22(76)$ & $<.001$ \\
\hline Facial pain/pressure & $0(0)$ & $2(4)$ & & $31(86)$ & $14(48)$ & $<.001$ \\
\hline Postnasal drip & $0(0)$ & $27(54)$ & & $23(64)$ & $22(76)$ & $<.001$ \\
\hline Nasal obstruction & $0(0)$ & $41(82)$ & & $24(67)$ & $27(93)$ & $<.001$ \\
\hline B. & $\begin{array}{c}\text { Control } \\
n=25\end{array}$ & $\begin{array}{c}\text { AR } \\
n=55\end{array}$ & $\begin{array}{c}\text { CRS } \\
n=30\end{array}$ & $\begin{array}{c}\mathrm{CRS}+\mathrm{AR} \\
\mathrm{n}=29\end{array}$ & $\begin{array}{c}\text { CRSwNP } \\
\mathrm{n}=15\end{array}$ & $p$ \\
\hline \multicolumn{7}{|l|}{ Current symptoms, n (\%) } \\
\hline Wheeze & $0(0)$ & $5(9)$ & $4(13)$ & $5(17)$ & $5(33)$ & .023 \\
\hline Loss of sense of smell & $2(8)$ & $9(16)$ & $6(20)$ & $6(21)$ & $9(60)$ & .005 \\
\hline Ocular irritation symptoms & $4(16)$ & $9(16)$ & $8(27)$ & $11(38)$ & $4(27)$ & .21 \\
\hline Sneeze & $3(12)$ & $22(40)$ & $9(30)$ & $12(41)$ & $5(33)$ & .10 \\
\hline Nose itching & $2(8)$ & $20(36)$ & $9(30)$ & $9(31)$ & $4(27)$ & .11 \\
\hline Nasal discharge & $8(32)$ & $18(33)$ & $10(33)$ & $15(52)$ & $10(67)$ & .08 \\
\hline Facial pain/pressure & $3(12)$ & $1(2)$ & $19(63)$ & $19(66)$ & $5(33)$ & $<.001$ \\
\hline Postnasal drip & $5(20)$ & $18(33)$ & $16(53)$ & $23(79)$ & $10(67)$ & $<.001$ \\
\hline Nasal obstruction & $9(36)$ & $25(46)$ & $19(63)$ & $24(83)$ & $15(100)$ & $<.001$ \\
\hline
\end{tabular}

\begin{tabular}{|c|c|c|c|c|}
\hline \multicolumn{5}{|c|}{ Positive responses } \\
\hline $0 \%$ & $1-25 \%$ & $26-50 \%$ & $51-75 \%$ & $76-100 \%$ \\
\hline
\end{tabular}


Table 3. Number and proportion (\%) of positive responses to the question: Which of the (off-seasonal) symptom(s) is/are the worst? (A.) in $\mathbf{n}$ four clusters obtained by Ward's method, (B.) in subject groups. The number of the reported worst symptoms, $\mathrm{n}(\%)$ are also shown. $p$ values by Fisher's exact test. $\mathrm{AD}=$ atopic dermatitis.

\begin{tabular}{ccccc} 
A. Asymptomatic & "Symptomatic \\
AR and controls" & $\begin{array}{c}\text { "Moderate } \\
\text { symptoms and } \\
\text { CRSsNP" }\end{array}$ & $\begin{array}{c}\text { "Severe } \\
\text { symptoms and } \\
\text { CRSwNP" }\end{array}$ \\
$\begin{array}{ccccc}\text { Cluster } 2 \\
\mathrm{n}=39\end{array}$ & $\begin{array}{c}\text { Cluster } 4 \\
\mathrm{n}=50\end{array}$ & $\begin{array}{c}\text { Cluster } 3 \\
\mathrm{n}=36\end{array}$ & $\begin{array}{c}\text { Cluster } 1 \\
\mathrm{n}=29\end{array}$ & $p$ \\
\hline
\end{tabular}

The worst symptom(s), $\mathrm{n}(\%)$

\begin{tabular}{|c|c|c|c|c|c|}
\hline Wheeze & $0(0)$ & $0(0)$ & $1(3)$ & $2(7)$ & .058 \\
\hline Loss of sense of smell & $0(0)$ & $1(2)$ & $0(0)$ & $2(7)$ & .18 \\
\hline Ocular irritation symptoms & $0(0)$ & $2(4)$ & $1(3)$ & $0(0)$ & .62 \\
\hline Sneeze & $0(0)$ & $3(6)$ & $0(0)$ & $1(3)$ & .22 \\
\hline Nose itching & $0(0)$ & $2(4)$ & $0(0)$ & $1(3)$ & .42 \\
\hline Nasal discharge & $1(3)$ & $3(6)$ & $3(8)$ & $3(10)$ & .53 \\
\hline Facial pain/pressure & $1(3)$ & $1(2)$ & $21(58)$ & $5(17)$ & $<.001$ \\
\hline Postnasal drip & $0(0)$ & $10(20)$ & $8(22)$ & $5(17)$ & .005 \\
\hline Nasal obstruction & $0(0)$ & $10(20)$ & $11(31)$ & $14(48)$ & $<.001$ \\
\hline \multicolumn{3}{|c|}{ The number of the reported worst symptoms, n(\%) } & & & $<.001$ \\
\hline 0 & $37(94.9)$ & $23(46.0)$ & $5(13.9)$ & $6(20.7)$ & \\
\hline 1 & $2(5.1)$ & $21(42.0)$ & $21(58.3)$ & $14(48.3)$ & \\
\hline $2-3$ & $0(0)$ & $6(12.0)$ & $10(27.8)$ & $9(31.0)$ & \\
\hline
\end{tabular}

$\begin{array}{cccccc}\text { Control } & \text { AR } & \text { CRS } & \text { CRS }+ \text { AR } & \text { CRSwNP } & p \\ n=25 & n=55 & n=30 & n=29 & n=15 & p\end{array}$

Current symptoms, $\mathrm{n}(\%)$

$\begin{array}{lcccccc}\text { Wheeze } & 0(0) & 0(0) & 1(3) & 1(3) & 1(7) & .24 \\ \text { Loss of sense of smell } & 0(0) & 1(2) & 0(0) & 0(0) & 2(13) & .05 \\ \text { Ocular irritation symptoms } & 1(4) & 1(2) & 0(0) & 1(3) & 0(0) & .70 \\ \text { Sneeze } & 0(0) & 2(4) & 1(3) & 1(3) & 0(0) & 1.0 \\ \text { Nose itching } & 0(0) & 2(4) & 0(0) & 1(3) & 0(0) & .85 \\ \text { Nasal discharge } & 0(0) & 3(6) & 3(10) & 2(7) & 2(13) & .40 \\ \text { Facial pain/pressure } & 0(0) & 0(0) & 15(50) & 11(38) & 2(13) & <.001 \\ \text { Postnasal drip } & 0(0) & 3(6) & 7(23) & 10(35) & 3(20) & <.001 \\ \text { Nasal obstruction } & 0(0) & 7(13) & 8(27) & 13(45) & 7(47) & <.001 \\ \text { The number of the reported worst symptoms, n(\%) } & & & & 1(6.7) & <.001 \\ 0 & 24(96.0) & 40(72.7) & 3(10.0) & 3(10.3) & 12(80.0)\end{array}$

\begin{tabular}{|c|c|c|c|c|}
\hline \multicolumn{5}{|c|}{ Positive responses } \\
\hline $0 \%$ & $1-25 \%$ & $26-50 \%$ & $51-75 \%$ & $76-100 \%$ \\
\hline
\end{tabular}




\section{Cluster 2}

Thirty-nine adults fell into this group, most (97.5\%) without CRS; $60 \%$ of healthy controls, and $43 \%$ of AR subjects. Only 3\% had current nose itching and $8 \%$ nasal discharge (Table 2), no other symptoms were seen. Only 2 (5\%) subjects reported having "the worst symptom" (Table 3). We named this group "Asymptomatic AR and controls".

\section{Cluster 3}

Thirty-six adults belonged to this cluster with the highest proportion of smokers (25\%, Table 1); $94.4 \%$ had CRSsNP, and $47.2 \%$ AR (Table 1). The subjects in this cluster reported the highest median value of antibiotic courses due to acute rhinosinusitis within last 2 years (Table 1), and moderate to severe symptoms with high variability; $86 \%$ reported having facial pain/pressure symptom (Table 2, Figure 2). Of the subjects in this cluster, $28 \%$ reported having more than one worst symptom, 58\% reported facial pain/pressure the worst or one of the worst symptoms (Table 3). We named this group "Moderate symptoms and CRSsNP".

\section{Cluster 4}

Fifty adults belonged to this cluster, with a significantly higher prevalence of self-reported AD (45\%). The majority (56\%) were subjects with AR without CRS, $28 \%$ had CRS, and $16 \%$ were healthy controls. The highest median number of months per year of AR symptoms were reported in this cluster (Table 1). This cluster was characterized by moderate to severe symptoms with variability (Table 2, Figure 2). Typical symptoms were nasal obstruction (82\%), postnasal drip (54\%), and sneeze (54\%). Nasal obstruction (20\%) and postnasal drip (20\%) were the most frequently reported worst symptoms (Table 3). We named this group "Symptomatic and having AD".

Associations of clusters with other factors are shown in Table 1. The differences of symptoms between clusters and original subject groups are presented in Tables 2-3 and Figure 2.

\section{The effect of atopic dermatitis on airway symptom score}

When observing all subjects without CRS, the median sum of nine current off-seasonal symptoms was significantly higher in the subgroup $\mathrm{AD} \pm \mathrm{AR}$, compared to AR-only and healthy control groups (Figure 3). AD associated significantly with the higher sum of nine symptoms, independently of confounding factors: gender, age, $\mathrm{AR}$ and sensitization pattern $(\mathrm{OR}=2.06, \mathrm{OR}=1.31-3.24, p=0.002$; adjusted $\mathrm{OR}=2.11$, $\mathrm{CI}=1.19-3.74, p=0.01)$.

When observing only the group of subjects with AR without CRS, the median (IQR) sum of nine current off-seasonal symptoms was 3 (1-5) if there was co-existing $\mathrm{AD}$, whereas the median (IQR) sum of nine current off-seasonal symptoms was 0 (0-3.5) in AR only subgroup ( $p=0.016)$.

In CRS patients, the presence of $\mathrm{AD}$ and /or $\mathrm{AR}$ did not affect the median sum of the nine symptoms or the median sum of the four VAS scores $(p>0.05)$. Nor did the presence of AD affect the median sum of VAS scores in non-CRS subjects ( $p>0.05$ by MWU test).

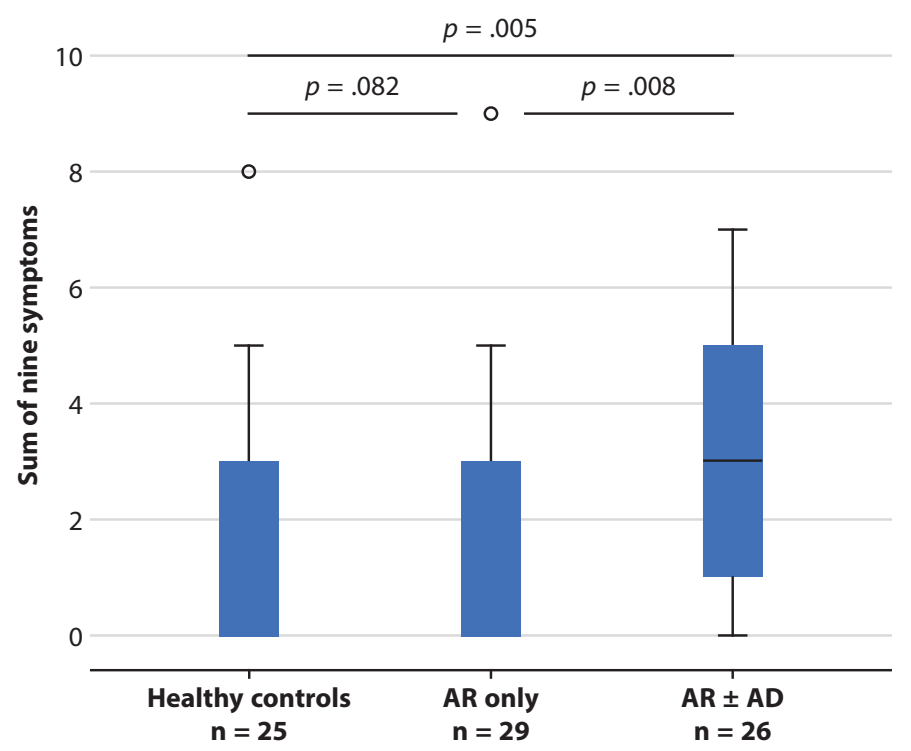

Figure 3. Boxplot showing the sum of nine symptoms in the subjects without CRS. The three subject groups were based on the presence af $\mathrm{AR}$ and/or $\mathrm{AD}$. The following nine symptoms were asked off-seasonally (yes, no): obstruction, postnasal drip, nasal discharge, sneezing, nasal itching, pain/pressure in the face or head, ocular symptoms, decreased sense of smell, dyspnea. The high sum of nine symptoms reflects high variablity of symptoms. AR = allergic rhinitis, $\mathrm{CRS}=$ chronic rhinosinusitis, $\mathrm{AD}=$ atopic dermatitis. The median values are shown by horizontal lines. $p$-values by MWU test.

\section{Discussion}

Uncontrolled upper airway allergy and related co-morbidities may lead to permanent modulations of the airways, and to a decrease in general health. By better understanding co-morbidities, endotypes, symptom variability and disease control, management can be improved and patients benefiting from new treatments, such as biologicals, could better be identified. ${ }^{2,7,16-19}$

This study was carried out to evaluate if unsupervised hierarchical clustering can be used to distinguish chronic inflammatory upper airway disease phenotypes based on the presence of NP, off-seasonal allergic symptoms, and selfreported background characteristics, and to observe characteristics of the obtained clusters. The benefit of hierarchical clustering is, that it helps to avoid a priori bias, since a mathematical algorithm performs the classification of patients into groups. The choice of variables used for clustering understandably affects the results. We used variables, similar to those used in prior similar studies, that we assumed would best relate to a rhinitis phenotype, and best represent off-seasonal airway symptoms and clinical findings. Unlike some studies, we did not use biomarkers, such as eosinophilia. ${ }^{19,26-29}$ Focus was set on the role of $\mathrm{AD}$, as $\mathrm{AD}$ showed to be one of the important factors in cluster analyses and as there is limited knowledge on AD's role as co-morbid condition of adult upper airway diseases. ${ }^{20}$ Phenotyping of AR patients by cluster analysis has previously not resulted in clinically relevant information. ${ }^{30}$ The method has proven useful in hierarchical clustering of both pediatric and adult patients, 
in mild and severe asthma. ${ }^{28,29}$ It has also successfully been used to determine CRS phenotypes. ${ }^{26,27}$ We named the obtained clusters so that they would best describe its characters compared to the other clusters.

In our study, CRSwNP and CRSsNP phenotypes were distinguished by clustering methods, when using symptoms and clinical signs as variables. No statistically significant difference was seen in how symptomatic the patients with both CRS and AR were compared to those with only CRS (Figure 2). Although about half of the patients in the clusters "Severe symptoms and CRSwNP" and "Moderate symptoms and CRSsNP" had co-existing AR, the presence of AR did not affect the formation of these clusters. This might be because the symptoms of CRSsNP and CRSwNP phenotypes alone are strong and characterize the clusters, whereas AR does not affect the symptom profile out of pollen season.

The cluster "Severe symptoms and CRSwNP" showed many, variable sinonasal symptoms, the highest median sum of VAS scores, and the highest median sum of symptoms, loss of sense of smell was common. Unlike in prior literature, the patients in this cluster trended to have the highest Lund-Mackay score on sinus CT scans. CT scans are usually considered necessary for preoperative evaluation, but not for assessment of symptom severity in CRS, due to the lack of proof of association between symptom severity and Lund-Mackay scores. ${ }^{31,32}$

Facial pain was common (86\%) in subjects of cluster "Moderate symptoms and CRSsNP". They reported highly variable, moderate to severe symptoms, had the highest median value of antibiotic courses due to acute rhinosinusitis, and the highest proportion of smokers (25\%). These results are similar to previous results: patients with CRSsNP have been reported to have more facial pain, whereas those with CRSwNP to have more nasal symptoms and obstruction. ${ }^{33}$ The CRSsNP phenotype seems to be more heterogeneous than CRSwNP. ${ }^{31}$

In Finland, the major reason for AR are pollens, the season of which is between March and August. House dust mite allergy is uncommon in Finland, ${ }^{3,4}$ The study data was collected between September and February, i.e. outside of allergy season. The AR group included seasonal AR subjects who did not report persistent AR or CRS. We initially hypothesized that the AR group is relatively asymptomatic and clustered closely to healthy controls when using off-seasonal symptoms as variables. In contrast to our preliminary hypothesis, we detected that $\mathrm{AD}$ increased the risk of off-seasonal upper airway symptoms in AR subjects, yet this requires more studies to be proven. Previous studies show that uncontrolled AR may lead to the development of CRS or other co-existing diseases, such as asthma, reducing the quality of life. ${ }^{2}$ Although the role of asthma is well recognized in inflammatory upper airway diseases, there is only scarce knowledge of the role of $\mathrm{AD}$ in adults. ${ }^{20,34}$

Polysensitization is frequently seen in young adult asthmatics with co-existing AR. ${ }^{4}$ In our study, sensitization pattern did not associate with clusters or phenotypes. This might be in part due to the fact that SPT was performed only on $18 \%$ of the CRS group and $88 \%$ of the control group.
It is possible that the off-seasonal sinonasal symptoms of the group with $\mathrm{AR}$ and $\mathrm{AD}$ might be related to sensitization to allergens not tested. On the other hand, this group suffered from a large variety of sinonasal symptoms and not only from AR symptoms. Moreover the SPT for basic aeroallergens, used in this study, covers the main allergens in Finland.

We found healthy controls were relatively well distinguished by clustering methods. Interestingly, AR fell into two main clusters; $42 \%$ of the AR subjects into "Asymptomatic AR and controls", and half of the AR patients into "Symptomatic and having AD". The off-seasonal symptoms and the presence of co-existing $\mathrm{AD}$ distinguished $\mathrm{AR}$ subjects between these clusters. Hence, it seems that AR has several subtypes. Adults with co-existing $\mathrm{AR}$ and $\mathrm{AD}$ complained more frequently of off-seasonal airway symptoms, even when they didn't have CRS. Further comparison and adjusted logistic regression analyses showed similar results, but only in the non-CRS subjects. Hence, co-existing AD and AR might be a more severe phenotype than only AR. This group might benefit from increased clinical care of the upper airways, however, further studies are needed to confirm this. Allergic multimorbidity has recently been studied in adults and in children. ${ }^{4-6,35}$ Eczema, rhinitis and asthma coexist in children, irrespective of IgE sensitization; it seems that IgE sensitisation cannot be considered the main causal mechanism of this comorbidity. ${ }^{9}$ The pathomechanisms behind co-existing AR and atopic dermatitis $(\mathrm{AD})$ remain unknown. Children with co-existing rhinitis and $\mathrm{AD}$ have more symptoms due to nonallergic irritants compared to those with rhinitis without AD. ${ }^{9}$ Neurogenic inflammation is present both in $\mathrm{AD}$ and in rhinitis and may have a role in their coexistence. ${ }^{12}$ Further studies are warranted on the role of $\mathrm{AD}$ in $\mathrm{AR}$ patients, and on neurogenic inflammation in $\mathrm{AD}$ and in rhinitis.

Adult asthmatics with co-existing $\mathrm{AR}$ and/or allergic conjunctivitis (AC) associate with a polysensitization pattern. $\mathrm{AR} / \mathrm{AC}$ asthma might be "a true" allergic phenotype, whereas asthmatic adults with sensitization to a single allergen with no allergic symptoms might not be related to allergic asthma. ${ }^{35}$ Similar results as in this study could be anticipated also in other allergic diseases - the role of $\mathrm{AR}, \mathrm{AD}, \mathrm{AC}$ and asthma, in phenotype and endotype formation, deserves further studies.

The limitations of our study include lack of validated and general health related quality of life questionnaire, and small number of CRS patients with SPT results. CRS patients represented a random sample of tertiary care including asthmatics, smokers and patients with general diseases. To simplify our study model, subjects with asthma, general diseases or smoking were excluded from the control group. Thus, we were not able to study the confounding effect of all allergic co-morbidities (such as asthma) or, smoking, or general diseases on the association between symptoms and $\mathrm{AD}$ in the control group. We acknowledge that selection bias is possible, since the control group of volunteers was not a random sample, and the study was not population-based. However, by using strict inclusion criteria, we were able to detect association between $\mathrm{AD}$ and off-seasonal upper airway symptoms of nonCRS adults. Further studies with increased number of subjects 
and larger variety of allergic multimorbidities are needed to demonstrate whether these phenomena are mostly related to AR only or to also other allergic diseases.

\section{Conclusions}

Hierarchical clustering can distinguish inflammatory upper airway disease phenotypes. CRSwNP, CRSsNP and asymptomatic control phenotypes might be distinguishable based on off-seasonal symptoms and clinical information, whereas AR phenotype is not. AR+ AD may be a distinct phenotype showing more off-seasonal upper airway symptoms than AR-only phenotype. Adult AR+ AD patients could benefit from active clinical care of the upper airways also off-season.

\section{Ethical considerations}

The study was approved by the ethical committees of Pirkanmaa Hospital district (R06187, R07039), and Helsinki University Hospital district (nro 376/13/03/01/10). Written informed consent was obtained from all patients.

\section{Consent for publication}

Not applicable.

\section{Availability of data and material}

The datasets used and analysed during the current study are available from the corresponding author on reasonable request.

\section{Competing interests}

The authors declare that they have no competing interests.

\section{Funding}

The study was supported in part by research grants from the Ahokas Foundation, Competitive Research Funding of the Tampere University Hospital (Grants 9H067, 9J108, 9L087), the Finnish Medical Society Duodecim, the Finnish Cultural Foundation, the Tampere Tuberculosis Foundation, the Finnish Society of Allergology and Immunology, State funding for university-level health research, the Ida Montin Foundation, the Jane and Aatos Erkko Foundation, the Väinö and Laina Kivi Foundation, the Finnish ORL-HNS Foundation, and the Yrjö Jahnsson Foundation.

\section{Author contributions}

S T-S provided the study plan, made the applications, recruited the subjects and performed nasal endoscopy. S T-S and $\mathrm{TH}$ performed the data management, A L-H and S T-S wrote the manuscript. All authors critically reviewed the manuscript.

\section{Acknowledgements \\ Not applicable.}

\section{References}

1. Hellings PW, Fokkens WJ, Akdis C, Bachert C, Cingi C, Dietz de Loos D, et al. Uncontrolled allergic rhinitis and chronic rhinosinusitis: where do we stand today? Allergy. 2013;68(1):1-7.

2. Brozek JL, Bousquet J, Agache I, Agarwal A, Bachert C, Bosnic-Anticevich $\mathrm{S}$, et al. Allergic Rhinitis and its Impact on Asthma (ARIA) guidelines -2016 revision. J Allergy Clin Immunol. 2017;140(4):950-8.

3. Koivikko A, Kupias R, Makinen Y, Pohjola A. Pollen seasons: forecasts of the most important allergenic plants in Finland. Allergy. 1986;41(4): 233-42.

4. Toppila-Salmi S, Huhtala H, Karjalainen J, Renkonen R, Makela MJ, Wang DY, et al. Sensitization pattern affects the asthma risk in Finnish adult population. Allergy. 2015;70(9):1112-20.

5. Cingi C, Gevaert P, Mosges R, Rondon C, Hox V, Rudenko M, et al. Multi-morbidities of allergic rhinitis in adults: European Academy of Allergy and Clinical Immunology Task Force Report. Clin Transl Allergy. 2017;7:17.

6. Gough H, Grabenhenrich L, Reich A, Eckers N, Nitsche O, Schramm $\mathrm{D}$, et al. Allergic multimorbidity of asthma, rhinitis and eczema over 20 years in the German birth cohort MAS. Pediatr Allergy Immunol. 2015;26(5):431-7.

7. Fokkens WJ, Lund VJ, Mullol J, Bachert C, Alobid I, Baroody F, et al. European Position Paper on Rhinosinusitis and Nasal Polyps 2012. Rhinol Suppl. 2012 (23)(23):3, 1-298.

8. Han H, Roan F, Ziegler SF. The atopic march: current insights into skin barrier dysfunction and epithelial cell-derived cytokines. Immunol Rev. 2017;278(1):116-30.

9. Baek JH, Cho E, Kim MA, Lee SW, Kang YS, Sheen YH, et al. Response to Nonallergenic Irritants in Children With Allergic and Nonallergic Rhinitis. Allergy Asthma Immunol Res. 2016;8(4):346-52.

10. Tomljenovic D, Baudoin T, Megla ZB, Vagic D, Hellings P, Kalogjera L. Nasal and ocular responses after specific and nonspecific nasal challenges in seasonal allergic rhinitis. Ann Allergy Asthma Immunol. 2016;116(3):199-205.

11. Segboer CL, Holland CT, Reinartz SM, Terreehorst I, Gevorgyan A, Hellings PW, et al. Nasal hyper-reactivity is a common feature in both allergic and nonallergic rhinitis. Allergy. 2013;68(11):1427-34.

12. Hellings PW, Klimek L, Cingi C, Agache I, Akdis C, Bachert C, et al. Non-allergic rhinitis: Position paper of the European Academy of Allergy and Clinical Immunology. Allergy. 2017; 72(11): 1657-65.

13. Hastan D, Fokkens WJ, Bachert C, Newson RB, Bislimovska J, Bockelbrink A, et al. Chronic rhinosinusitis in Europe--an underestimated disease. A GA2LEN study. Allergy. 2011;66(9):1216-23.

14. Hedman J, Kaprio J, Poussa T, Nieminen MM. Prevalence of asthma, aspirin intolerance, nasal polyposis and chronic obstructive pulmonary disease in a population-based study. Int J Epidemiol. 1999;28(4):717-22.

15. Settipane GA, Chafee FH. Nasal polyps in asthma and rhinitis. A review of 6,037 patients. J Allergy Clin Immunol.1977;59(1):17-21.

16. Tomassen P, Vandeplas G, Van Zele T, Cardell L, Arebro J, Olze H, et al. Inflammatory endotypes of chronic rhinosinusitis based on cluster analysis of biomarkers. J Allergy Clin Immunol. 2016;137(5):1449-56.

17. Hellings PW, Fokkens WJ, Bachert C, Akdis CA, Bieber T, Agache I, et al. Positioning the principles of precision medicine in care pathways for allergic rhinitis and chronic rhinosinusitis - A EUFOREA-ARIA-EPOS -AIRWAYS ICP statement. Allergy. 2017;72(9):1297-1305.

18. Koskinen A, Salo R, Huhtala H, Myller J, Rautiainen M, Kaariainen J, et al. Factors affecting revision rate of chronic rhinosinusitis. Laryngoscope Investig Otolaryngol. 2016;1(4):96-105.

19. De Greve G, Hellings PW, Fokkens WJ, Pugin B, Steelant B, Seys SF. Endotype-driven treatment in chronic upper airway diseases. Clin Transl Allergy. 2017; 7: 22.

20. Bousquet J, Agache I, Aliberti MR, Angles R, Annesi-Maesano I, Anto JM, et al. Transfer of innovation on allergic rhinitis and asthma multimorbidity in the elderly (MACVIA-ARIA) - EIP on AHA Twinning Reference Site (GARD research demonstration project). Allergy. 2018; 73(1): 77-92.

21. Julkunen A, Terna E, Numminen J, Markkola A, Dastidar P, Karjalainen $\mathrm{M}$, et al. Inter-observer agreement of paranasal sinus computed tomography scans. Acta Otolaryngol. 2017;137(6):611-17.

22. Koskinen A, Numminen J, Markkola A, Karjalainen J, Karstila T, Seppala $\mathrm{M}$, et al. Diagnostic Accuracy of Symptoms, Endoscopy, and Imaging Signs of Chronic Rhinosinusitis Without Nasal Polyps Compared to Allergic Rhinitis. Am J Rhinol Allergy. 2018;32(3):121-31. 
23. Renkonen J, Toppila-Salmi S, Joenvaara S, Mattila P, Parviainen V, Hagstrom J, et al. Expression of Toll-like receptors in nasal epithelium in allergic rhinitis. APMIS. 2015;123(8):716-25.

24. Honkanen T, Luukkainen A, Lehtonen M, Paavonen T, Karjalainen J, Hurme $\mathrm{M}$, et al. Indoleamine 2,3-dioxygenase expression is associated with chronic rhinosinusitis with nasal polyps and antrochoanal polyps. Rhinology. 2011;49(3):356-63.

25. Koskinen A, Penttila M, Myller J, Hammaren-Malmi S, Silvola J, Haahtela $\mathrm{T}$, et al. Endoscopic sinus surgery might reduce exacerbations and symptoms more than balloon sinuplasty. Am J Rhinol Allergy. 2012; 26(6): e150-6.

26. Soler ZM, Hyer JM, Ramakrishnan V, Smith TL, Mace J, Rudmik L, et al. Identification of chronic rhinosinusitis phenotypes using cluster analysis. Int Forum Allergy Rhinol. 2015;5(5):399-407.

27. Nakayama T, Asaka D, Yoshikawa M, Okushi T, Matsuwaki Y, Moriyama $\mathrm{H}$, et al. Identification of chronic rhinosinusitis phenotypes using cluster analysis. Am J Rhinol Allergy. 2012;26(3):172-6.

28. Schatz M, Hsu JY, Zeiger RS, Chen W, Dorenbaum A, Chipps BE, et al. Phenotypes determined by cluster analysis in severe or difficult-to-treat asthma. J Allergy Clin Immunol. 2014;133(6):1549-56.

29. Haldar P, Pavord ID, Shaw DE, Berry MA, Thomas M, Brightling CE, et al. Cluster analysis and clinical asthma phenotypes. Am J Respirat Crit Care Med. 2008;01;178(3):218-24.
30. Bousquet PJ, Devillier P, Tadmouri A, Mesbah K, Demoly P, Bousquet J. Clinical relevance of cluster analysis in phenotyping allergic rhinitis in a real-life study. Int Arch Allergy Immunol. 2015;166(3):231-40.

31. Greguric T, Trkulja V, Baudoin T, Grgic MV, Smigovec I, Kalogjera L. Association between computed tomography findings and clinical symptoms in chronic rhinosinusitis with and without nasal polyps. Eur Arch Otorhinolaryngol. 2017;274(5):2165-73.

32. Holbrook EH, Brown CL, Lyden ER, Leopold DA. Lack of significant correlation between rhinosinusitis symptoms and specific regions of sinus computer tomography scans. Am J Rhinol. 2005;19(4):382-7.

33. Greguric T, Trkulja V, Baudoin T, Grgic M, Smigovec I, Kalogjera L. Differences in the Sino-Nasal Outcome Test 22 and visual analog scale symptom scores in chronic rhinosinusitis with and without nasal polyps. Am J Rhinol Allergy. 2016;30(2):107-12.

34. Bousquet J, Bachert C, Canonica GW, Casale TB, Cruz AA, Lockey RJ, et al. Unmet needs in severe chronic upper airway disease (SCUAD). J Allergy Clin Immunol. 2009;124(3):428-33.

35. Adjers K, Luukkainen A, Pekkanen J, Hurme M, Huhtala H, Renkonen $\mathrm{R}$, et al. Self-Reported Allergic Rhinitis and/or Allergic Conjunctivitis Associate with IL13 rs20541 Polymorphism in Finnish Adult Asthma Patients. Int Arch Allergy Immunol. 2017;172(2):123-8. 